\title{
La reforma educativa de Enrique Peña Nieto: ¿Política pública en blanco y negro?
}

\author{
Enrique Peña Nieto's Educational Reform: \\ Public policy in black and white?
}

Salvador Camacho Sandoval ${ }^{1}$

\section{Resumen}

\begin{abstract}
Desde una perspectiva interdisciplinaria y usando varias técnicas de investigación, este texto analiza la instrumentación de la política educativa del gobierno de Enrique Peña Nieto (2012-2018). Se retoma la tesis de que la política pública es un conjunto de medidas de Estado que se modifican en su instrumentación a partir de la intervención y los intereses de los actores involucrados, y cuestiona la visión dicotómica y extremista que se tiene sobre la reforma educativa, para lo cual se presentan resultados de un estudio de opinión que da cuenta de la complejidad y diversidad que ha tenido la aplicación de estas medidas. Como sucedió en otros momentos de la historia de la educación en México, el resultado de la reforma ha sido producto de las resistencias y negociaciones de dichos actores, y su impacto aún no termina.
\end{abstract}

Palabras clave: historia del presente, política educativa, reforma y actores de la educación

\section{Abstract}

From an interdisciplinary perspective and using various research techniques, this article analyzes the implementation of the educational policy of Enrique Peña Nieto's government (2012-2018). The author employs the thesis that public policy is a set of State measures which are modified in their instrumentation by the intervention and interests of the actors involved and, thus, questions the dichotomous and extremist vision of the educational reform; this, with the aim of presenting the results of an opinion study, that shows the complexity and diversity that the application of these measures has had. As it has happened in other moments in the history of education in Mexico, the result of the reform has been the product of the resistance and negotiations of these actors. Its impact has not yet ended.

\section{Keywords: present history, educational policy, reform and actors of education}

\footnotetext{
${ }^{1}$ Universidad Autónoma de Aguascalientes. Correo electrónico: camacho_sal@yahoo.com.mx
} 
El propósito de este texto es ofrecer un análisis crítico de las discusiones en torno a la reforma educativa que impulsó el gobierno de Enrique Peña Nieto y que rechazó el gobierno de Andrés Manuel López Obrador. Lo hago desde lo que ahora se ha llamado "historia del tiempo presente" 2 de la educación y a partir de opiniones de autoridades, directores de escuela y profesores que fueron partícipes en la instrumentación de dicha reforma. Se parte de la tesis de que la historia de la educación proporciona una perspectiva de análisis útil que nos acerca a una mayor comprensión del origen, desarrollo y resultados de las políticas educativas, en este caso la política educativa que formó parte del Pacto por México, signado por los partidos Revolucionario Institucional (PRI), Acción Nacional (PAN) y de la Revolución Democrática (PRD), el 2 de diciembre de 2012 (Excélsior, 2012).

La reforma educativa de Peña Nieto formó parte de un proyecto modernizante del gobierno federal y tuvo un consenso importante al inicio del sexenio, de manera que, como ya se dijo, congregó a las principales fuerzas políticas del país; sin embargo, casi al final del sexenio, esta reforma no cumplió lo que prometió y el nuevo grupo en el poder mantuvo un discurso de total rechazo. "Ni una coma quedará de la reforma educativa", aseguró amenazante el coordinador de Morena en la Cámara de diputados" (Delgado, 2018). ¿Qué fue lo que pasó? ¿Por qué una reforma que pudo ganar simpatías entre los maestros y la ciudadanía no tuvo el impacto deseado? ¿Cuáles fueron sus resultados? ¿Todas las medidas de política educativa del gobierno de Peña Nieto tenían que ser anuladas? ¿Realmente, no debería quedar "ni una coma" de la reforma educativa?

La intención de este trabajo es tener más y mejores elementos de comprensión de la política educativa del gobierno de Peña Nieto y que rechazó el de Andrés Manuel López Obrador, de manera que se evite concebir esta experiencia compleja desde una perspectiva dicotómica, de negro o blanco, tal como se vio en las múltiples discusiones que tuvieron lugar, sobre todo en época de campaña electoral. Como se señaló en reiteradas ocasiones, uno de los objetivos centrales de la reforma constitucional era atender la calidad de la educación, vista como un derecho individual y una necesidad social. En concreto, perseguía, según el propio texto gubernamental, propiciar y fortalecer la equidad y garantizar la calidad de la educación pública obligatoria, para lo cual tuvo como estrategias principales la creación de un servicio profesional docente y el establecimiento del Sistema Nacional de Evaluación Educativa, con un instituto con autonomía (Gobierno de la República, 2014).

Según Grindle (citada en Martínez, 2018), las reformas de los años setenta y ochenta del siglo pasado, tuvieron como propósito central aumentar la cobertura, construir escuelas y crear nuevas plazas para maestros, para lo cual tanto autoridades como sindicatos lo aceptaban sin mayor discusión. A partir de los años noventa, dice la autora, el énfasis se puso

\footnotetext{
2 El término Historia del Presente (HTP) es acuñado en los años sesenta del siglo XX por un grupo de historiadores franceses para diferenciarlo de la historia contemporánea y contradecir la idea de que "Desde 1830 no hay historia, hay política" (Bédarida, 1998).
} 
en la calidad, pero en este rubro ya no hubo coincidencias fáciles entre los actores educativos; por eso se les llamó "reformas difíciles", que, además, involucraban a todo un país e impactaban a otras esferas de la sociedad, como la economía y la cultura.

Con base en las investigaciones de Michael Lipsky, las políticas públicas no son monolíticas, sino decisiones mediadas por distintos actores, quienes las implementan de acuerdo a sus intereses, objetivos, negociaciones, interpretaciones y opiniones que tienen sobre los asuntos en cuestión y su futuro. Lipsky puso atención en aquellas personas que trabajan en la burocracia y que son finalmente los responsables de llevar a cabo las decisiones tomadas desde arriba, es la burocracia a nivel de calle, "street level bureaucracy", según sus palabras (Lipsky, 1980). Éste y otros autores también señalan que estos actores adaptan a su práctica las acciones propuestas, pero que, además, pueden dosificar estas medidas por diferentes causas, incluso sabotearlas (Dussauge, Cejudo y Pardo, 2018). Por esto mismo, para un análisis del origen, instrumentación y resultados de las políticas, hay que identificar las necesidades y características de los distintos grupos involucrados en su diseño y ejecución. Su desempeño puede hacer la diferencia entre la política gubernamental en teoría y la política gubernamental en la práctica.

Esta idea parte de una definición de política pública. De acuerdo con Fernández (2005: 467), los "anglosajones distinguen entre politics y policies". La primera expresión concibe la política como construcción del consenso y lucha por el poder, mientras la segunda se utiliza para denominar las actividades gubernamentales más concretas en campos específicos como la salud, la defensa nacional y la educación. En las lenguas de origen latino existe el término política(s) para hacer alusión a actividades con propósitos políticos, decisiones gubernamentales, programas de acción o resultados de determinado proyecto gubernamental. Por esta razón, se hace uso de la traducción de la expresión policy por política pública.

Además, una cosa es lo que se dice y otra es lo que se hace. Theodore Sorensen, todo un personaje en el gobierno y vida del presidente John F. Kennedy, escribió, a partir de su rica experiencia en la política norteamericana, en 1963, lo siguiente:

Los pasos no se dan en orden. Los hechos están en duda o en disputa. Las políticas,
todas buenas, se contradicen. Los medios, todos malos, pueden ser los únicos dispo-
nibles, Los juicios de valor difieren mucho de lo descrito; [además, existen] múltiples
interpretaciones de lo que es bueno y lo que es malo (citado en Cárdenas, 2010: 13).

Más aún, un entendimiento de la reforma educativa y su instrumentación, o si se quiere de las medidas de política educativa, también tiene que considerar el contexto económico, sociocultural y político en el que trabajan el gobierno federal y los gobiernos estatales que están a cargo de ella. Por eso no es posible disociar lo pedagógico de lo político y social. Hay 
que insistir que hablar de educación es también referirnos a grupos de poder con ideologías distintas y proyectos de sociedad diferentes que se enfrentan entre sí en la arena pública.

Pensemos en México en la época posrevolucionaria, cuando el grupo en el poder quiso reconstruir un Estado debilitado por la lucha armada e impartió una educación, entre 1921 y 1940, que tuvo como propósito formar ciudadanos leales a un proyecto a favor del reparto de tierra, la reivindicación obrera, a una visión laica de la vida pública y, en suma, a acelerar procesos modernizadores con medidas de justicia social. Había propósitos, pero, como lo ha señalado Mary Kay Vaughan, "la escuela se convirtió en el campo de batalla de negociaciones intensas y con frecuencia violentas por el poder...", y en el proceso algunos de los grupos y comunidades crearon espacios para conservar sus respectivas identidades e intereses (Vaughan, 2000: 19).

Es por esto que no podemos hablar sólo de lo educativo. La reforma educativa de Peña Nieto es la continuidad o, por lo menos, es un referente fundamental de la reforma modernizadora que inició Miguel de la Madrid y, sobre todo, Carlos Salinas de Gortari en los años ochenta y noventa: cercana a la economía y abierta al mundo (Camacho, 2002), y que pretendió tener la fuerza y el impacto que tuvieron otras, como la de José Vasconcelos en 1921, al crearse la Secretaría de Educación Pública (SEP); o la impulsada por Jaime Torres Bodet en 1959, con los libros de texto gratuitos y el Plan de Once años. Tanto las decisiones de Salinas de Gortari como las de Peña Nieto fueron parte de la visión modernizante de los llamados tecnócratas, que buscaron con las herramientas de la planeación y la academia, apegarse a un proyecto de nación asociado a formar ciudadanos preparados para involucrarse a una economía competitiva en un mundo global exigente, para lo cual la educación es uno de los principales instrumentos de apoyo.

Es por esto, que, para algunos, México desde los años ochenta del siglo pasado ha intentado y se ha visto obligado a subirse al tren de los procesos modernizadores, so pena de quedar marginado de los beneficios económicos y culturales que ofrece el mundo de la globalización. Esto no significa, por otra parte, que el gobierno de Peña Nieto pretendiera privatizar la educación y eliminar el laicismo, como algunos grupos de izquierda lo dijeron 3 . En suma, para mí, la reforma era necesaria, tuvo aciertos; pero, al final, fue limitada, sin consenso entre el magisterio y políticamente fracasó.

\section{El origen y la confrontación}

El gobierno federal y el presidente de la República llegaron a un descrédito preocupante al final del sexenio. La aprobación de Enrique Peña Nieto fue muy baja desde 2015 y siguió cayendo entre la ciudadanía y líderes de opinión hasta 2018. Según la encuesta Consulta

\footnotetext{
${ }^{3}$ En este sentido, coincido con Sylvia Schmelkes de que la reforma no pretendió privatizar la educación (Schmelkes, 2016), sin negar que hubo tendencias que fortalecían al sector privado en educación.
} 
Mitofsky, en noviembre de ese año, sólo el 24\% de la gente aprobó su gestión y el $76 \%$ la desaprobó. En agosto el porcentaje había sido del 18\% (El Economista, 2018), uno de los porcentajes más bajos entre los presidentes en el mundo.

Además, entre la población existió una percepción y una preocupación real de que la pobreza y la violencia habían aumentado en el país. La militarización y la guerra contra el narcotráfico desplegada con el entonces presidente Felipe Calderón Hinojosa (2006-2012) también había fracasado; al igual que el combate a la corrupción, un fenómeno asociado a la impunidad jurídica y social. El actual presidente ha tomado medidas en contra de la corrupción, pero tal fenómeno es complejo y está muy arraigado en la población, forma parte de su cultura (Zalpa 2014).

Pero los problemas del país no sólo son de violencia y corrupción, el proyecto de nación que tuvieron los últimos presidentes no atendió de fondo los graves problemas de desigualdad social de los mexicanos. Más allá del discurso del gobierno actual, falta ver si realmente existe un proyecto de nación que tenga la fortaleza suficiente para dar un mejor rumbo a la economía del país, de manera que se tenga una mayor producción de bienes y servicios y una mejor distribución de la riqueza. No basta incrementar los índices de productividad sino hay un beneficio para quienes generan riqueza con su trabajo, y México destaca por ser uno de los países con más desigualdad interna en el mundo.

En este contexto de desaliento es que se puso a la Reforma educativa como un asunto importante en la campaña electoral de 2018. Desde el gobierno, hubo optimismo por dicha reforma y se resaltaron sus características. Otto Granados Roldán, siendo titular de la SEP, por ejemplo, dijo que la reforma educativa era "la más importante en el país en muchos años". Textualmente declaró en su discurso de inicio del ciclo escolar 2018:

\footnotetext{
Al menos en los últimos 60 años, juicio de propios y extraños, esta ha sido la reforma educativa más importante que se ha realizado. Una reforma cuyo peso moral, político, pedagógico y ético no se puede negar y porque en ella está depositada la educación de que millones de niños y jóvenes alcancen su máximo potencial y tengan una vida buena. Celebremos el inicio de este nuevo ciclo escolar, muy seguros de que hicimos lo que teníamos que hacer y que lo hicimos muy bien (Granados, 2018).
}

El mismo pronunciamiento lo hizo Aurelio Nuño Mayer, ya como extitular de la SEP. Para él, dicha reforma respondió a las exigencias de un país que se había transformado demográfica, social, política y económicamente de manera radical en los últimos 30 años. También dijo textualmente que "era necesario comenzar por recuperar la rectoría del Estado", lo que "implicaba una reorganización de la relación entre el magisterio y las autoridades para dejar atrás un sistema opaco y clientelar, eliminando prácticas inaceptables como la herencia y la venta de plazas" (Nuño, 2018). 
La oposición a la reforma educativa, la expresó abiertamente la Coordinadora Nacional de Trabajadores de la Educación (CNTE), la cual presentó propuestas:

Proponemos una educación humanista que sustituya los valores del mercado por la práctica de valores universales.

(..)

Se trata, además, de convertir al proceso educativo en un espacio de creatividad, exploración y participación, libre de rigideces y fincado en la curiosidad, el compromiso responsable de maestros, estudiantes y de la comunidad; y en el interés y compromiso solidario de los niños y jóvenes por lo que ocurre a su alrededor.

(..)

Rechazamos la concepción de que la educación es un ejercicio de subordinación donde el estudiante es sólo un alumno pasivo que recibe información y que luego debe dar cuenta de ella en un examen estandarizado. (La hoja de arena, s/f).

La CNTE manejó un discurso de izquierda y antineoliberal. Por lo demás, estos planteamientos, como muchos otros, no se opusieron, en sentido estricto, a la legislación educativa mexicana ni a lo expresado por la SEP desde hace muchos años. Se puede decir, aún en tiempos del PAN en el poder, que la normativa y la narrativa educativa en la SEP no varió mucho. Otra cosa fueron los hechos, sobre todo en algunos estados donde los gobiernos de extracción panista cedieron espacios de política educativa a la Iglesia católica y organizaciones conservadoras como el Opus Dei y los Legionarios de Cristo (Camacho, 2004).

En esta oposición de la CNTE, además, había otro motivo: algunos líderes quisieron recuperar el control político y financiero de los sistemas educativos estatales que el gobierno federal les había arrebatado. Algo semejante ocurrió en el Sindicato Nacional de Trabajadores de la Educación (SNTE), pero sus dirigentes, que habían disminuido su poder con el encarcelamiento de su lideresa, mantuvieron lealtad al gobierno, aún cuando sabían de la inconformidad manifiesta o velada de miles de profesores por las evaluaciones a las que fueron sometidos, asunto en el cual la CNTE fue mucho más beligerante en su oposición. Para esta organización era reprobable el tipo de evaluación que la SEP aplicaba a los profesores, pues, según sus líderes era "un proceso autoritario, vertical, centrado en torno a las autoridades y con rasgos laborales persecutorios y represivos claramente en contra del 123 constitucional" Por esto proponían:

Una evaluación horizontal realizada desde las propias escuelas y comunidades, desarrollada como un ejercicio dialógico a nivel de cada zona, región y entidad federativa. Una evaluación que, al mismo tiempo que describe los problemas, analiza los factores que los causan, los remedios que pueden darse y recoge las experiencias exitosas de maestros y escuelas para mejorar la educación (La Hoja de Arena, s/f). 
Las manifestaciones de oposición y resistencia del magisterio a la evaluación no fueron exclusivas del caso mexicano, pues esto ocurrió, con diferente intensidad, en otros países de América Latina, por no hablar de otras regiones del mundo (Sánchez y Corte, 2015).

El cuestionamiento a la reforma educativa, y específicamente a la evaluación docentes, también lo hicieron algunos académicos; por ejemplo, Ángel Díaz Barriga, investigador emérito de la UNAM, dijo que ésta no era una reforma educativa, sino una reforma que partía de un "modelo caótico" y autoritario, con una evaluación del desempeño docente que agredía y humillaba a las maestras y maestros (Díaz, 2017). Otra voz fue la de Elsie Rockwell, quien dijo que la reforma tenía un carácter vertical y forzado que trastocaba las dinámicas de colectivos de maestros y que tenía una lógica que no era educativa, porque la trascendía e involucraba fuertes intereses políticos y económicos. El gobierno decía respetar los derechos de los niños y jóvenes, pero en los hechos los violaba con medidas que homogenizaban y violentaban la administración escolar, además de que distraía a los docentes de su tarea principal, que era la enseñanza. Contrario a la visión oficial, según ella, la reforma estaba polarizando aún más el sistema educativo y fortaleciendo la privatización, dando por resultado "un descenso dramático de la calidad y equidad de la educación pública" (El país, 2017).

Otra opinión fue la de Carlos Ornelas, quien dijo que los problemas educativos estaban dentro de los males del México posrevolucionario, como el corporativismo, el clientelismo y el patrimonialismo. En particular, analizó la relación entre el SNTE y el gobierno federal, con Miguel de la Madrid y luego con Salinas de Gortari, y recordó que para aplicar el Acuerdo Nacional para la Modernización de la Educación Básica, Salinas de Gortari tuvo que quitar al líder vitalicio de este sindical, Carlos Jonguitud, y poner en su lugar a Elba Esther Gordillo, que públicamente apoyó la reforma pero en los hechos movilizó a los maestros para evitar algunos cambios (Ornelas, 2018).

La señora Gordillo adquirió tanto poder que prácticamente se apropió de la SEP y de la mayoría de las secretarías de la educación en los estados durante el gobierno de Felipe Calderón. Todo ello como premio porque supuestamente ella lo llevó a la presidencia de la República por medio de los votos que le dio su partido (Nueva Alianza). Ella forzó al presidente para quitar a Josefina Vázquez Mota de la SEP e impuso a su yerno en la Subsecretaría de Educación Básica, la subsecretaría más importante y con más dinero en esta dependencia de gobierno.

Años después, con el desprestigio social de la política educativa impulsada por el gobierno de Felipe Calderón y Elba Esther Cordillo, denominada Alianza para la Calidad Educativa, ni el PAN ni el PRI vieron en la maestra Gordillo a una aliada clave en las elecciones de 2012, en las que ganó Enrique Peña Nieto. Más, aún, tal como lo hizo Salinas de Gortari con el líder petrolero la Quina, el nuevo presidente encarceló a la maestra el 26 de febrero de 2013; quería ganar legitimidad, recuperar para el Estado la rectoría de la educación e instrumentar una reforma educativa "a favor de la calidad educativa". Y en este proceso, el 
gobierno asumió que la evaluación del desempeño de los maestros era fundamental para mejorar. La Ley del Servicio Profesional Docente ocupó, entonces, mucho espacio, que luego se revirtió en contra del gobierno y de su reforma.

En este afán de recuperar la rectoría de la educación, el SNTE aceptó las nuevas reglas del juego, pero al mismo tiempo se reorganizó para seguir controlando parcelas de la administración de los servicios educativos en todo el país. De allí el nombre de "neocorporativismo", que parece estar vigente y vigoroso, pues continúa usando "sus armas favoritas: chantaje, amenaza y extorsión", vicios que se oponen al avance democrático de la educación y del país (Ornelas, 2018: 213). La CNTE, a su vez, que había sido una organización que surgió reivindicando la democracia interna del SNTE, con el tiempo sus líderes no cambiaron estrategias corporativas y clientelares. Algunos de ellos han sido tan autoritarios y caciquiles como los que habían criticado. Con el apoyo ofrecido al actual presidente de la República lograron posicionarse en el sistema educativo y obtener puestos relevantes.

\section{La transición y el futuro inmediato}

Se insistió mucho en que la reforma educativa era una reforma laboral y administrativa, pero no educativa, y había mucho de razón en ello, pues inicialmente no hubo cambios estructurales en el sistema educativo: el modelo educativo llegó tarde y, entre otras cosas, la negociación con el magisterio y su organización sindical no fue la mejor, de manera que, a pesar de la campaña publicitaria costosa del gobierno en los medios de comunicación, las bondades de la reforma no calaron en el sector educativo, mucho menos en la sociedad. Esto implicó poner en las propuestas los planes y programas de estudio, los libros de texto, la formación inicial y actualización del profesorado, la organización administrativa y la gobernanza del sistema, entre otras.

También se anunciaron recortes financieros que imposibilitaron las mejoras sustantivas en la infraestructura y equipamiento escolar y en la contratación de personal en todos los niveles educativos y en las modalidades importantes, como la educación de adultos, la educación indígena, la educación para personas con capacidades especiales y la capacitación para el trabajo.

Lo que sobresalió en política educativa de Peña Nieto fueron los cambios en el sistema de ingreso, promoción, reconocimiento y permanencia de profesores, directores y otros actores escolares de educación básica y media superior, los cuales dependieron de los resultados de evaluaciones externas. Todo esto era parte de los resultados de las reformas a los artículos $3^{\circ}$ y 73 de la Constitución Política, las modificaciones a la Ley General de Educación y la creación de la Ley del Instituto Nacional de Evaluación Educativa y, muy especialmente, de la Ley General del Servicio Profesional Docente. 
Esta última fue rechazada por Elba Esther Gordillo, lo cual sumaba un punto más en su contra, de manera que fue encarcelada no por corrupta, sino porque representaba un impedimento para llevar a cabo la reforma educativa. El PAN siempre había sido uno de los partidos más críticos del SNTE y de sus formas de proceder, pero no le importó cuando fue necesario en momentos electorales. A cambio de votos, el grupo panista ya en el gobierno compartió decisiones. Desde la perspectiva de la lideresa, el acuerdo fue el siguiente: "En ese escenario vino la sucesión y llegamos al acuerdo de ir con el presidente Calderón por la Presidencia de la República, previos arreglos de orden político que no deben avergonzar a nadie. A mí no me avergüenzan, yo hago política”, dijo categórica (Gordillo, 2018).

En 2014 se habló de que con el encarcelamiento de Gordillo y la exclusión de los líderes del SNTE en las secretarías estatales y especialmente de la dirigencia de la CNTE en el Instituto Estatal de Educación Pública en Oaxaca en julio de 2015, se había recuperado la rectoría del Estado en materia educativa. Ahora sabemos que estas fuerzas sindicales negociaron con Andrés Manuel López Obrador para recuperar espacios perdidos. En 2019 , las autoridades del Instituto Nacional de Evaluación Educativa (INEE) dijeron que el Estado debía continuar al frente de la rectoría y conducción del sistema educativo nacional, evitando que se volviera a "ser presa de intereses de pocos y relegue la calidad de la educación pública". También decían que nunca se debía "privilegiar a grupos particulares que solo (veían) una forma de promover sus intereses y no los de la niñez del país" (Ortega, 2019).

Con todo, es imperioso distinguir a los líderes sindicales del magisterio; más aún, dentro de éste hay que reconocer una pluralidad de ideas, identidades, formaciones y tipo de trabajo, que suelen olvidar académicos, políticos y los mismos profesores. Esta diversidad de grupos tampoco fue atendida en la Reforma de Peña Nieto. La consigna fue evaluar a todos y ser exigentes, aunque las consecuencias no gustaran. Los alumnos tenían derecho a tener buenos maestros y sólo se sabría a partir de los resultados de esas evaluaciones, se dijo entonces. La consigna era amenazante, "proempresarial": "evaluación con consecuencias", bajo la idea de que los maestros reprobados o con un perfil "no idóneo" debían ser capacitados o removidos. Ante la crítica a este tipo de evaluación, desde los espacios de la organización "Mexicanos primero", David Calderón escribió: "los funcionarios en México son pudorosas jovencitas a las que no se les puede tocar ni con el pétalo de un ranking" (Calderón, 2009).

Eso con respecto a la desvinculación de los y las maestras en la elaboración y aplicación de la evaluación y, en general, de la Reforma. Desde otro ángulo, la Asociación de Padres de Familia y Mexicanos Primero, que se atribuían ciertas libertades para hablar en nombre de la ciudadanía, sintieron suya la reforma. Desde el sector académico hubo personas involucradas, sobre todo en el INEE, cuya junta directiva estuvo conformada por investigadores educativos reconocidos en el país. El desempeño de este organismo también fue cuestionado por la oposición y dividió a la comunidad crítica de investigadores de la educación. Según una investigadora, en cierto momento el INEE estuvo "internamente fragmentado, socialmente 
cuestionado y funcionalmente desbordado" (Citado por Flores, 2018). Con la llegada del gobierno de López Obrador, el INEE fue visto como parte del gran engaño de la "no reforma educativa" y fue desaparecido. Parte de sus actividades pasaron a formar parte del Organismo Coordinador del Sistema Nacional de Mejora Continua de la Educación, que ya no tiene autonomía y que no sólo se dedicará a la evaluación.

La reforma educativa de Peña Nieto tuvo un mal de origen: en su perspectiva y elaboración se tomó en cuenta a una corriente tecnocrática y conservadora, encabezada por empresarios aglutinados en Mexicanos Primero, que influyeron en la percepción de los problemas educativos y participaron en la definición del tipo de medidas que debían instrumentarse en el sistema educativo, en particular para exigir un mejor trabajo a los profesores, como parte pasiva dentro de una estructura vertical que no consideraba su participación como actores directos de la educación. Se negó la colaboración o intromisión de los líderes sindicales, pero también de otras fuerzas dentro y fuera del sistema educativo.

A pesar de estos vacíos, errores y dificultades, la política educativa del gobierno de Peña Nieto tuvo logros y avances importantes para beneficio del sistema educativo y, por consiguiente, de las y los alumnos mexicanos. Un análisis de blanco y negro no ayuda a tener un conocimiento de la realidad y, por tanto, impide diseñar líneas de trabajo y niega un diálogo fructífero con los tomadores de decisiones. Muestra de estos logros es que en la propuesta educativa del nuevo gobierno federal ha tenido continuidad, tan es así que un diputado dijo que el $80 \%$ del contenido de la nueva reforma era igual a la anterior.

Luis Hernández Navarro, del diario La Jornada, quien mucho criticó la política educativa de Peña Nieto, textualmente dijo: "El dictamen aprobado en la Cámara de Diputados, es un dictamen que retoma los puntos centrales de la Reforma de Peña Nieto... es como cambiar la carrocería de un carro, pero no el motor, y luego venderlo como nuevo" y esto no puede ser parte de la Cuarta Transformación ${ }^{4}$ (Hernández, 2019). La Nueva Escuela Mexicana del presidente Manuel López Obrador tiene una de sus expresiones en una reiterada acusación al neoliberalismo y un enunciado endeble de propósitos en el Plan Nacional de Desarrollo 2019-2024 (Presidencia de la República, 2019) y en la ausencia de un programa sectorial.

Otro elemento de continuidad es el centralismo del sistema educativo. En 2012, todavía durante el gobierno de Felipe Calderón Hinojosa, a pesar de que en la misma SEP había reticencias, el poder legislativo le dio obligatoriedad constitucional a la educación media y en el sexenio de Peña Nieto hubo una recentralización de la administración del recurso

${ }^{4}$ El término se refiere a la visión que tiene López Obrador sobre su futuro gobierno, que quiere situarlo al nivel de otros tres momentos de la historia de México: a) la Independencia (1810-1821): el movimiento armado para liberarse de los 300 años de dominio español; b) La Reforma (1858-1861): la guerra entre liberales y conservadores; "Leyes de Reforma", entre las que destaca la separación de la Iglesia y el Estado. Benito Juárez, el personaje que más admira López Obrador, fue el protagonista de este momento; y c) La Revolución: conflicto armado contra el régimen de Porfirio Díaz entre 1910 y 1917, año en que se promulgó la Constitución que rige actualmente en México (BBC News Mundo, 2018). 
financiero, afectando tendencias favorables al federalismo mexicano. Cuando se descentralizó el sistema educativo, en 1992, en el gobierno de Carlos Salinas de Cortari, los gobernadores tuvieron la posibilidad de tomar decisiones importantes: designaban a las autoridades educativas y ejercían el recurso en programas que los gobiernos estatales creían prioritarios. Hubo gobernadores y autoridades educativas que impulsaron proyectos valiosos y ejemplares, que justificaban la descentralización (Camacho, 2002); pero hubo otros que desviaron los recursos y tomaron decisiones perjudiciales. De allí la iniciativa, entre otros motivos, de re-centralizar, tendencia que parece acentuarse con el presidente López Obrador.

La derogación de la ley del servicio profesional docente puede propiciar la desaparición del sistema meritocrático en el acceso y promoción de los trabajadores de la educación y la vuelta a los vicios consabidos. La reforma inicialmente atendió la evaluación como instrumento de mejora y la profesionalización del magisterio. Se pretendió que el INEE se fortaleciera como un organismo que ayudará a desarrollar estrategias nuevas para conocer el nivel de aprovechamiento y logros de alumnos, escuelas y profesores, para luego hacer las mejoras correspondientes. Ahora se puede decir que faltaron muchas cosas por hacer; como evitar las pruebas estandarizadas que no consideraron diferencias regionales y culturales; explorar otras formas de evaluación internas a las escuelas, en las que participara el profesor; retroalimentar efectivamente a los profesores de manera que su evaluación no sólo impactara en su ingreso salarial, sino también en su práctica docente; etc.

De la evaluación a profesores, directivos y supervisores, parece correcto que sean las capacidades académicas y menos la antigüedad de la persona, por ejemplo, las que prevalezcan como criterios centrales. Es inadmisible que muchos de estos importantes actores de la educación accedan y permanezcan en el mundo escolar gracias a lealtades, amistades, herencias familiares e, incluso, compra de plazas y puestos. Con 102 votos a favor y 22 en contra, el Senado de la República aprobó el dictamen que expidió la ley del servicio profesional docente, la cual pretendía también, según el entonces senador del PAN, ofrecer una mejor formación, capacitación y actualización de los programas (Romero, 2013), pero no se cumplió del todo.

Con el propósito de ordenar el sector educativo también se aplicó un censo nacional, con el apoyo del Instituto Nacional de Estadística y Geografía (INEGI), para conocer quiénes constituían el sistema educativo y para determinar las necesidades de infraestructura. A su vez, el INEE realizó diagnósticos útiles sobre diversos aspectos de la educación en México y, junto con el Consejo Nacional de Ciencia y Tecnología (CONACYT), impulsó la investigación educativa. En suma, el INEE, a pesar de su burocracia, errores y presunta falta de autonomía, mantuvo un nivel de profesionalismo en un trabajo que no se había tenido antes, y que fue desaparecido sin presentar una mejor alternativa.

Parte intrínseca de estas medidas fue la estrategia política del gobierno federal que marcó cierto deslinde con los líderes del SNTE y la CNTE. Esto fue clave, porque, como se 
dijo al principio, la política educativa tiene que ver con las alianzas y confrontación de grupos de interés que determinan rumbos en el sistema educativo. Esta demarcación, condujo a una reestructuración en el tipo de relaciones y, según algunos, creó un nuevo corporativismo y el regreso de grupos que parecían derrotados.

\section{Opiniones que relativizan}

Durante el gobierno de Enrique Peña Nieto hubo mucha discusión sobre la reforma educativa. Se escuchó a los líderes sindicales, a los expertos en educación y, sobre todo, a las autoridades de la SEP y directivos del INEE; sin embargo, se escucharon poco las opiniones de quienes estaban aplicando lo que se acordó en la cúpula de tomadores de decisiones. Según Fernández (2005), se pueden identificar dos enfoques en la implementación de políticas públicas: uno es el enfoque "top down", que no es otra cosa que tomar decisiones desde la autoridad gubernamental para que otros, en este caso los profesores, hagan lo que "desde arriba" decidieron. Este enfoque, según el autor, genera procesos de control que procuran resultados eficaces y eficientes.

El otro enfoque es el "bottom up", que pone especial énfasis en los actores, con sus objetivos, oportunidades y fortalezas y debilidades. Sus partidarios destacan el papel de los intereses locales y la adaptación o no de los programas, a partir de los intereses y capacidades de estos actores educativos. En otras palabras, este enfoque toma en consideración a quienes participan en la aplicación de medidas, a la "burocracia a nivel de calle", que construye y puede, en los hechos, desviar, adaptar o hacer fracasar los programas (Lipsky, 2008), pese al esfuerzo de la jerarquía política y administrativa.

Con este planteamiento, se elaboró una investigación para conocer la experiencia y opiniones de profesores y directores de educación media y autoridades del Instituto de Educación de Aguascalientes, usando dos instrumentos: una encuesta derivada del método Delphi ${ }^{5}$, aplicada a 63 personas y luego a 32 de ellas, y 30 entrevistas a profundidad (Camacho, 2019). Por razones de espacio, se retoman únicamente algunas frases sobre lo que ellos consideraron aspectos relevantes de la aplicación de la reforma educativa de 2013, que también fue entrelazada con la Reforma Integral de Educación Media Superior, de 2008, todo ello en el marco de la transición política y gubernamental, marcada por el triunfo de una "izquierda moderada".

En las entrevistas hubo acuerdo en señalar que era importante hacer cambios porque había problemas y rezagos en el sistema educativo, en especial en las escuelas de educación media. Se vio que la reforma de 2013 tenía aspectos positivos; por ejemplo, se reconoció la

\footnotetext{
${ }^{5}$ El método o técnica Delphi tiene distintas aplicaciones, como el análisis de propuestas concernientes a las políticas públicas o una herramienta de previsión; organiza y clarifica puntos de vista de manera anónima para facilitar y complementar el trabajo de los tomadores de decisiones. (Turoff \& Linstone, 2002).
} 
atención que se puso a la formación socio afectiva de los alumnos, toda vez que había problemas acuciantes, como los de la drogadicción y los embarazos no deseados. De los cuestionarios aplicados con el Método Delphi, también se tuvo consenso de que había un interés gubernamental por atender aspectos que antes no formaban parte de los objetivos de la educación en México.

Del Nuevo Modelo Educativo que se presentó al final del sexenio, tanto los entrevistados como los que respondieron a los cuestionarios Delphi, coincidieron en señalar logros, aunque también algunos de ellos señalaron que no había claridad sobre las estrategias para formar a los estudiantes en varias competencias, como las habilidades socio afectivas. Textualmente, uno de los participantes en la encuesta afirmó: "Hay una eficiente inclusión de actividades socioemocionales". Otro puso atención en la importancia que tiene el personal de apoyo: "los tutores y orientadores se incorporaron al trabajo escolar promoviendo mejores resultados académicos y un buen desarrollo de aspectos socio afectivos". Sin embargo, muchos coinciden en señalar que también hay vaguedad en los cómo y en el tipo de participación que deben tener los actores educativos en las escuelas.

Una de las personas encuestadas opinó que "la descomposición social afecta a los procesos formativos que pretenden desarrollarse en la escuela" y que, frente a problemas de carácter estructural, los esfuerzos escolares, expresados en tutorías y otras acciones planteadas en la reforma, no eran suficientes. Muchos de los participantes en el estudio dijeron tener conocimiento de la problemática que enfrentaban los estudiantes; pero, de igual manera, reconocieron que no hubo claridad de cómo instrumentar adecuadamente los programas; todo ello en un ambiente de dudas sobre el rumbo que seguía la reforma educativa en las escuelas mexicanas.

En un ejercicio de jerarquización, los participantes en el estudio Dephi señalaron de más a menos importancia los aspectos siguientes: el curriculum, la pertinencia de los contenidos educativos (que es parte del curriculum), la formación docente, la evaluación de los docentes, el proceso enseñanza - aprendizaje, la infraestructura educativa, las tareas administrativas, la evaluación de los alumnos, la situación laboral de los trabajadores de la educación, el aprovechamiento escolar y el contexto social. Llama la atención que el aprovechamiento escolar de los alumnos esté en penúltimo lugar de importancia.

Desde otra perspectiva, la mayoría de los encuestados están de acuerdo con las siguientes afirmaciones, mismas que fueron definidas textualmente por ellos: "Debe dejarse de ver a la educación como un sistema politizado y de negocios, y que sea un proyecto de Estado"; "La reforma es inadecuada en México porque ésta se originó en el extranjero donde existe un contexto muy diferente al nacional"; "No hay una difusión adecuada de la Reforma"; "La reforma es laboral y no se relaciona al trabajo en el aula", y "No hay congruencia entre lo ofertado por la Reforma y lo realizado en las escuelas y aulas". 
De manera más específica, los encuestados, están de acuerdo con estos señalamientos: "Falta la profesionalización de la docencia"; "Hace falta una capacitación de calidad para los profesores"; "No se propicia la promoción de profesores y directivos mediante la evaluación"; "No hay una evaluación auténtica y honesta"; "Existe una mala aplicación de la promoción docente y directiva, hay manipulación de los procesos"; "No hay estabilidad y seguridad laboral para los profesores"; "Falta disposición por parte de las autoridades de escuchar a los docentes"; "No hay reconocimiento ni apoyo por parte de las autoridades a las labores del docente"; "No se ha atacado el problema de reprobación de manera eficiente"; "La descomposición social afecta a los procesos formativos que pretenden desarrollarse en la escuela", y "El manejo de recursos (económicos y materiales) es deficiente".

Las personas encuestadas dudan, o no hay consenso, en cuanto a que: "El Programa de Estímulos al Desempeño Docente en las escuelas de educación media ha sido positivo", "No hay estrategias sólidas y de impacto real que disminuyan las problemáticas de nivelación de los alumnos" y "La Reforma es laxa, paternalista y los maestros son tradicionalistas".

Hasta aquí la visión y opiniones de estos actores educativos. Tal como lo señalan quienes han aplicado el Método Delphi y han hecho entrevistas, la percepción de quienes ejecutan medidas de políticas públicas es muy importante, porque son ellos los que pueden cumplir con los objetivos y hacer realidad ciertas aspiraciones de mejora, en este caso en el incremento de los indicadores de la cobertura y la calidad de la educación que se ofrece a los niños, niñas y jóvenes de México. Desde luego, cada uno de los aspectos antes señalados merece investigarse a fondo, pero lo que queda claro es la opinión negativa que tienen estos maestros de algunos lineamientos de la política educativa impulsada por el gobierno de Peña Nieto y de una realidad educativa que va más allá de la reforma educativa, y que forma parte de una problemática estructural, cuyas causas son complejas e involucran a otros actores sociales.

\section{Consideraciones finales}

La historia de la educación nos enseña que las reformas educativas son limitadas y que con ellas no se mejora de la noche a la mañana el sistema educativo; pero que, concretadas en leyes consensuadas con los actores de la educación, tienen más posibilidades de tener resultados, aunque sean modestos. El derecho a la educación de calidad es un derecho no cubierto a cabalidad en los niños y jóvenes mexicanos. Existen evidencias de que hay obstáculos que impiden que los alumnos tengan una formación acorde a su realidad individual, familiar y social. En las escuelas primarias el nivel de aprovechamiento sigue siendo bajo y en secundarias y, sobre todo de educación media, un porcentaje importante de jóvenes continúa abandonando sus estudios y muchos de los que permanecen no logran contar con conocimientos y competencias relevantes para su vida. Los resultados del cuestionario aplicado a 
directores y profesores indican que existe una serie de problemáticas que tienen un trasfondo político y social que hace más difícil su solución.

Como aquí se ha señalado, hay una tendencia hacia el cuestionamiento de las autoridades y las reformas educativas, y un reconocimiento de problemas que no han sido resueltos del todo con las medidas de política educativa. Alguien podrá decir que las opiniones no necesariamente concuerdan con los hechos y no están sustentadas con datos duros, porque en sus expresiones hay una carga de subjetividad. Esto es verdad; no obstante, son estas experiencias personales las que tienen sentido en la medida que impactan en la práctica docente cotidiana. También, dichas opiniones ofrecen un panorama sobre la distancia que hay entre lo que deciden desde el gobierno y lo que perciben y ejecutan decisiones de política educativa.

El estudio que involucra a profesores muestra que la reforma en su diseño y aplicación tuvo importantes aciertos, pero también errores, vacíos y contradicciones, lo cual impide asumir una posición dicotómica de la misma. En otras palabras, la reforma se constituyó y se instrumentó en una escala de grises, por lo que obliga a no hacer cambios extremos, sin un previo análisis riguroso. Los cambios sexenales abruptos sin conciencia del valor de las continuidades, seguro impacta negativamente al sistema educativo, afectando a toda comunidad escolar y propiciando que los resultados de aprendizajes de los alumnos sigan estancados.

Otro punto a resaltar es que los profesores y directores de escuela son capaces, con o sin intenciones claras, de modificar el rumbo de la política, incluso de anular e impedir la aplicación de ciertos programas. Está por ver en detalle qué está pasando en las escuelas con la reforma que fue abrogada por el gobierno que encabeza Andrés Manuel López Obrador, y también qué de lo que se presenta como nuevo forma parte de lo anterior. Los profesores encuestados cuestionaron de la reforma de 2013 la manera como se les evaluó, pero también afirmaron que fueron positivas algunas medidas, como poner énfasis en el derecho a la educación, el avance por recuperar la rectoría del sistema educativo por parte del Estado mexicano, la apuesta a mejorar la calidad de la educación, exigiendo (que no imponiendo) mejoras en la formación y desempeño de los profesores, tanto de educación básica como de educación media superior.

La necesidad de una mejor formación de los profesores y directores tuvo ciertos consensos entre los entrevistados y encuestados, en el sentido de valorar positivamente la importancia de la profesionalización del servicio docente; aún más, hubo maestros y directores que dijeron que una evaluación exigente era necesaria para determinar quiénes pueden ser profesores, directores y supervisores, y a quiénes hay que promover y reconocer. En este sentido, en las leyes secundarias deben quedar claros los procesos de selección de maestros, mediante concursos públicos, transparentes, equitativos e imparciales, y que los nombramientos sean únicamente otorgados conforme a esta normativa.

Al nuevo gobierno le toca revisar críticamente las reformas y retomar lo que de suyo ha tenido de positivo, desde una perspectiva de Estado, más allá de las diferencias políticas. No 
es admisible echar por la borda todo lo que los gobiernos anteriores hicieron, atendiendo únicamente a la inconformidad de grupos magisteriales por el tipo de evaluación a la que fueron sometidos. Se requiere retomar a las políticas públicas como acciones que tienen objetivos de interés social y que deben surgir de un diagnóstico y de un análisis de factibilidad para atender con efectividad problemas y demandas específicas, asumiendo que participan los ciudadanos y los directamente involucrados (¿quién en materia de educación no está involucrado?) Y esto es imperativo en un país que se abre a la democracia y que, por ende, retoma y reconstruye la naturaleza pública del gobierno y trata de liberarlo de ciertos grupos de interés que lo han mantenido en cautiverio (Aguilar, 1992: 23).

Por todo esto, para finalizar, surgen algunas interrogantes: ¿la propuesta del gobierno de López Obrador dista mucho de lo que se venía haciendo? ¿Hasta qué punto la rectoría de la educación es del Estado o nuevamente se está cediendo a las presiones de líderes sindicales? ¿Cuál ha sido la participación de la ciudadanía y del magisterio en la elaboración de diagnósticos y definición de objetivos y metas? De cara al futuro, ¿qué enseñanzas deja la historia del presente de la educación para proyectar la reforma educativa que necesita el país en cuanto a mejorar la economía y las condiciones socioculturales de sus habitantes? Frente a una tendencia de centralizar otra vez el sistema educativo, con el nombre de federalismo, ¿qué responsabilidades les toca atender a los gobiernos estatales y municipales? ¿Cómo diagnosticar necesidades y proponer cambios con una estructura centralizada en la SEP? ¿Cuáles son los márgenes para fortalecer las capacidades de gestión y acción de los gobiernos estatales para mejorar sus sistemas educativos? ¿Cuál será la participación de la sociedad, organizada en asociaciones y grupos de padres de familia, asociaciones no gubernamentales, grupos empresariales y de trabajadores, instituciones académicas y de investigación?

Se requiere conocer en detalles el contenido de las nuevas leyes y los programas. Tendrán que ser radicales, en el sentido de ir al fondo de los problemas. No es exagerado decir que hace falta impulsar, como en tiempos de la posrevolución, una gran cruzada, un gran movimiento social a favor de una educación de calidad para todos. La Cuarta Transformación debe expresarse también en el sistema educativo; este gobierno ha generado muchas expectativas y su presidente es uno de los más populares del mundo, pero aún no se tiene una política educativa a la altura de lo que se espera y de lo que México necesita. 


\section{Fuentes}

Aguilar, Luis (1992), El estudio de las politicas públicas, Miguel Ángel Porrúa, México.

BBC News Mundo (2018), "AMLO presidente: ¿qué es la "Cuarta Transformación" que propone Andrés Manuel López Obrador para México?, 26 de noviembre, Inglaterra, disponible en: https://bbc. in/206T6e7

Bédarida, Francois (1998), "Definición, método y práctica de la historia del presente", Cuadernos de Historia Contemporánea, Universidad Complutense de Madrid, № 20, España, pp. 83-98.

Calderón, David (2009), "Evaluación y consecuencias", Mexicanos Primero, 8 de julio, México, disponible en: https://bit.ly/2KffnTM

Camacho, Salvador (2002), Modernización educativa en México, 1982-1998. El caso de Aguascalientes, UAA - IEA, México.

Camacho, Salvador (2004), Educación y alternancia política en México. Los casos de Guanajuato y Aguascalientes, UAA-SIHCO, México.

Camacho, Salvador (2019), ¿Cómo se aplica la Reforma Integral de Educación Media Superior (RIEMS) y la Reforma educativa de 2013? Evaluación desde la gestión escolar en subsistemas federales y estatales en Aguascalientes. Reporte de Investigación, UAA/INEE/CONACYT, México.

Cárdenas, Sergio (2010), "El Programa Escuelas de Calidad", Educare, SEP, Edición especial, diciembre, México, pp. 13-15.

Delgado, Mario (2018), "Ni una coma quedará de la reforma educativa", Excélsior, 13 de septiembre, México, disponible en: https://bit.ly/2NC2gyd

Díaz, Ángel (2017), "La reforma educativa, un proceso caótico", Alcanzando el conocimiento, Video, disponible en: https://bit.ly/2yNjDUi

Diario Oficial de la Federación (2013), "Decreto por el que se reforman los artículos 3o. en sus fracciones III, VII y VIII; y 73, fracción XXV, y se adiciona un párrafo tercero, un inciso d) al párrafo segundo de la fracción II y una fracción IX al artículo 3o. de la Constitución Política de los Estados Unidos Mexicanos", Diario Oficial de la Federación, 26 de febrero. México, disponible en: https://bit.ly/IJF8UKp

Diario Oficial de la Federación (2019), "Decreto de reforma constitucional en materia educativa", Diario Oficial de la Federación, Senado, 15 de mayo, México.

Dussauge, Mauricio, Guillermo Cejudo y María del Carmen Pardo (Eds.) (2018), La burocracia a nivel de calle. Una antología, CIDE, México.

El Economista (2018), "El sexenio de Peña Nieto cierra con una aprobación de 24", 22 de noviembre, México, disponible en: https://bit.ly/2POYyn4

El País, "México: La reforma educativa a debate Elsie Rockwell - Sylvia Schmelkes, El País, 20 de enero de 2017, España, disponible en: http://gmiradasmultiples.blogspot.com/2017/01.html

Excélsior (2012), "El Pacto por México", 2 de diciembre, México, disponible en: https:/www.excelsior. com.mx/topico/pacto-por-mexico

Fernández, Antoni (2005), Las políticas públicas. En C. Aguilera, J. Antón, L. Bouza-Brey, M. Caminal, J. Colomer, A. Fernández, P. Vilanova, Manual de Ciencia Política (463-485). Tecnos, España, disponible en: https://bit.ly/2K6PwNM

Flores, Pedro (2018), "Tres problemas del INEE", Educación Futura, 18 de abril, México, disponible en: https://bit.ly/2HKKKS4X

Gobierno de la República (2014), Reforma educativa, Gobierno de la República, México.

Gordillo, Elba Esther (2018),"10 momentos clave en la vida de Elba Esther Gordillo", El Financiero, 8 de agosto, México, disponible en: https://bit.ly/2KIONHd

Granados, Otto (2018), 24 horas, 20 de agosto, México, disponible en: https://bit.ly/2OtvD7w 
Hernández, Luis (2019), "Reforma Educativa de la 4T es igual en un 80\% a la de Peña Nieto", Aristegui, 10 de abril, México, disponible en: https://bit.ly/2KkyrPf

Instituto Nacional de Evaluación Educativa (2007), Seminario internacional de indicadores educativos. Conceptos, metodología y experiencias para la construcción del sistema de indicadores educativos, INEE, México.

Lipsky, Michael (1980), Street Level Bureaucracy: Dilemmas of the Individual in Public Services, Russell Sage Foundation, EU.

La Hoja de Arena (s/f), "Reforma educativa: propuesta del Ejecutivo vs. propuesta de la CNTE", México, disponible en: https://bit.ly/2OaPrZc

Martínez, Felipe (2018), "Políticas y reformas", en Camacho S. (coord.), La lechuza extraviada. Desencuentros, reformas educativas y magisterio, UAA, México, pp. 85-93

Nuño, Aurelio (2018), "Respuesta a nexos. La reforma educativa", nexos, 1 de noviembre, México, disponible en: https://www.nexos.com.mx/?p=39966.

Presidencia de la República (2019), Plan Nacional de Desarrollo, 2019-2024, Gobierno de México, México.

Ornelas, Carlos, (2018), La contienda por la educación. Globalización, neocorporativismo y democracia, FCE, México.

Ortega, Ariadna (2019), "Los pros y contras de la nueva reforma educativa, según el INEE y organizaciones", Expansión política, 28 de marzo. México, disponible en: https://bit.ly/2M2anE3

Ortegón, Edgar (2015), Políticas públicas: Métodos conceptuales y métodos de evaluación. Universidad Continental, Perú, disponible en: https://bit.ly/2SRT5tM

Romero, Juan Carlos (2013), Senado de la República. Boletín 020. 3 de septiembre, México, disponible en: https://bit.ly/2Yv3OmS

Turoff, Murray \& Linstone, Harold (2002), The Delphi Method Techiniques and Applications, EU, disponible en: https://bit.ly/2DOHYcM

Sánchez, Manuel y Francisca María del Sagrario Corte (2015), "La evaluación a la docencia: Algunas consecuencias para América Latina", Revista Mexicana de Investigación Educativa, COMIE, №67, octubre/diciembre, México, disponible en: https://bit.ly/2Yl3z48

Schmelkes, Sylvia (2016), "La reforma nunca habla de privatizar la educación: INEE", Milenio, 20 de marzo, México, disponible en: https://bit.ly/2YFMIAD

Vaughan, Mary Kay (2000), La politica cultural en la revolución: maestros, campesinos y escuelas en México, 1930-1940, FCE/SEP, México.

Zalpa, Genaro (2014), ¿No habrá manera de arreglarnos?: Corrupción y cultura en México, UAA Nostra Ediciones, México. 